\title{
Cryptogenic hemoptysis in children
}

\author{
Rahman A* \\ Associate Professor Pediatric Pulmonology. Bangabandhu Sheikh Mujib Medical University, Dhaka, Bangladesh
}

Hemoptysis is defined as the expectoration of blood or blood tinged sputum from the lower respiratory tract [1]. Although common in adults, hemoptysis is a rare presenting symptom in children. As children often swallow their sputum; therefore, hemoptysis may go unnoticed, diagnosis of pediatric hemoptysis can be challenging unless the bleeding is substantial [2]. Hemoptysis may be confused with hematemesis in children. As the diagnostic and treatment strategies differ markedly, the two sources must be differentiated. The blood in hemoptysis is bright red in color and may be admixed with sputum and frothy. The blood in hematemesis is dark red or brown and may be mixed with food particles and is commonly preceeded by vomiting or retching [1-2]. The $\mathrm{pH}$ of the hemoptysis is generally alkaline, while the $\mathrm{pH}$ of hematemesis is acidic [1]. Once hemoptysis is confirmed, the underlying causes then are to be explored.

The bleeding may occur from the large or small pulmonary vessels. Bleeding from the small vessels is known as diffuse alveolar hemorrhage [3]. There are various etiologies of hemoptysis in children , including- infection (pneumonia, tracheobronchitis, tuberculosis), foreign body aspiration, cystic fibrosis, bronchiectasis, idiopathic pulmonary hemosiderosis, congenital heart disease (Endocardial cushion defects, complex heart diseases, tetralogy of Fallot, truncus arteriosus,Transposition of great arteries), pulmonary vascular malformation (e.g. bronchial artery pseudo aneurysm), pulmonary arteriovenous fistula [2,4]. However, in some cases, the cause remains unknown even after clinical evaluation and detailed investigations, including radiologic imaging and bronchoscopy. These cases are defined as cryptogenic hemoptysis $(\mathrm{CH})[5,6]$ nearly $20-25 \%$ of hemoptysis cases are reported to be diagnosed as cryptogenic [4,7].

Infection accounts for up to $40 \%$ of hemoptysis cases where destruction of lung parenchyma and erosion of blood vessels results in hemoptysis [2]. The infection is usually bacterial in nature and consists of Streptococcus pneumonia, Staphylococcus aureus, M. Catarrhalis, klebsiella species, or Pseudomonas aeruginosa. Hemoptysis from aspergillus infection of the lungs either in the form of allergic bronchopulmonary aspergillosis (ABPA) or invasive aspergilliosis have also been reported in children [8].

Congenital heart disease can cause hemoptysis in children. Here hemoptysis occurs most frequently from resultant pulmonary vascular obstructive disease. The other pahology found are enlarged collateral bronchial circulation, erosion of a tortuous dilated bronchial artery into a bronchus, from rupture of an atherosclerotic bronchial artery plaque, or from localized pulmonary infarction at the bronchopulmonary anastomosis [9,1]. Isolated bronchial artery pseudo aneurysm was also identified as a source of hemoptysis [3]. Foreign body aspiration is another important cause of pediatric hemoptysis. Bleeding here results from the mechanical trauma to the respiratory epithelium or the ensuing inflammatory reaction, especially to vegetable matter [10].
Approximately $5 \%$ of patients with cystic fibrosis may present with massive hemoptysis due to bronchiectasis. The pathology here found are-hyperplasia, tortuosity and dilatation of bronchial arteries due to chronic inflammation and subsequent erosion of these dilated, thin walled bronchial vessels after successive pulmonary infections [1].

Idiopathic pulmonary hemosiderosis is a rare cause of small and recurrent hemoptysis, resulting from diffuse alveolar hemorrhage. It has a variable natural history and has been reported to have a high mortality [11]. Many patients develop iron deficiency anemia secondary to deposition of hemosiderin iron in the alveoli. In one study it was found that, about $58 \%$ of childhood hemoptysis results from pulmonary hemosiderosis [12]. Hemosiderin-laden alveolar macrophages (siderophages) are found on examination of sputum \& broncho alveolar lavage and also the lung biopsy shows numerous siderophages in the alveoli, without any evidence of pulmonary vasculitis, nonspecific/granulomatous inflammation, or deposition of immunoglobulins. Normo-complement urticarial vacuities has been observed in some children which is supposed to be the cause of hemoptysis [13].

Malignancy of respiratory tract, like endobronchial or pulmonary parenchymal malignancies, may rarely cause of hemoptysis in children. Tumors that may cause hemoptysis include bronchial carcinoid, bronchial adenoma, endobronchial metastasis, mediastinal teratomas, tracheal tumors, or bronchial arteriovenous malformations in children [14].

Hemoptysis was found in approximately $10 \%$ of the patients with long-term tracheostomy [15]. About $15.5 \%$ of the hemoptysis was described to related with tracheotomy [16]. In these cases, pink or redtinged secretions are found on suctioning the tracheobronchial tree.

Factitious hemoptysis is considered when the suggestive medical history or abnormal behavior is found in the child [17]. Covert biting of the buccal mucosa has been attributed to be the cause of bleeding in a study [18]. There are some other less common causes causing hemoptysis in children, such as bleeding from localized lesions in upper airways or bleeding into the lungs as like part of a systemic disease systemic lupus erythematosis, Good pasture's syndrome, pulmonary thromboembolism, hydatid cyst, and even duplication cyst of the stomach [19-22]. An isolated pulmonary arteritis or endobronchial endometriosis can lead to massive hemoptysis in children $[23,24]$.

*Correspondence to: Md. Atiar Rahman, Associate Professor, Pediatric Pulmonology, Bangabandhu Sheikh Mujib, Medical University, Dhaka, Bangladesh, E-mail: atiar777@yahoo.com

Received: March 19, 2018; Accepted: April 04, 2018; Published: April 07, 2018 
The amount of hemoptysis was categorized as mild $(<20 \mathrm{~mL} /$ day $)$, moderate $(20-99 \mathrm{~mL} /$ day), and massive $(\geq 100 \mathrm{~mL} /$ day or bronchial blood loss that causes hemodynamic or respiratory compromises). ${ }^{1}$ Hemoptysis, when severe and untreated, has a mortality rate of more than $50 \%$ [1]. With interventional radiological procedures and surgery, this rate has dropped to $7 \%-18 \%$ [25].

While hemoptysis is usually identified with the currently available diagnostic tools such as computed tomography (CT) scan and fibrotic bronchoscopy, $20-25 \%$ of cases remain classified as cryptogenic [26]. It represents a challenge to identify the etiology of cryptogenic hemoptysis and manage the patient with massive cryptogenic hemoptysis in emergency. Up to now, multidisciplinary approach, such as medical management especially together with bronchial artery embolization, has been effectively applied to the treatment of massive hemoptysis, and surgical treatment has seldom been employed [4].

\section{Reference}

1. Batra PS, Holinger LD (2001) Etiology and Management of Pediatric Hemoptysis. Arch Otolaryngol Head Neck Surg 127: 377-382. [Crossref]

2. Gaude GS. Hemoptysis in children. Indian Pediatric. 2010 Mar;47: 245-54. [Crossref]

3. Rusha Patel, Derek Uchida, Peter GF, Jeremy D. Meier (2014) Bronchial Artery Pseudoaneurysm as an Unsuspected Cause of Hemoptysis in a Pediatric Patient. Ann Otol, Rhinol \& Laryngol 123: 591-595. [Crossref]

4. Samara KD, Tsetis D, Antoniou KM, Protopapadakis C, Maltezakis G, Siafakas NM (2011) Bronchial artery embolization for management of massive cryptogenic hemoptysis: a case series. J Med Case Rep 5: 58-63. [Crossref]

5. Corder R (2003) Hemoptysis. Emerg Med Clin North Am 21: 421-435.

6. Mal H, Rullon I, Mellot F, Brugière O, Sleiman C, Menu Y, et al (1999) Immediate and long-term results of bronchial artery embolization for life-threatening hemoptysis. Chest 115: 996-1001. [Crossref]

7. Santiago S, Tobias J, Williams AJ (1991) A reappraisal of the causes of hemoptysis. Arch Intern Med 151: 2449-2451. [Crossref]

8. Crassad N, Halden H, Piens MA, Pondarre C, Hadden R, et al (2008) Invasive aspergillosis in a pediatric hematologic department: a 15-year review. Mycosis 51: 109116. [Crossref]

9. Haroutunian LM, Neill CA (1972) Pulmonary complications of congenital heart disease: hemoptysis. Am Heart $J$ 84: 540-549. [Crossref]
10. Dore ND, Landar LI, Hallam L (1997) Hemoptysis in healthy children due to unsuspected foreign body. J Pediatric Child Health 33: 448-450. [Crossref]

11. Dearborn DG (1997) Pulmonary hemorrhage in infants and children. Curr Opin Pediatric 9: 219-224.

12. Kabra SK, Bhargava S, Lodha S, Satyavani A, Walia M (2007) Idiopathic pulmonary hemosiderosis: clinical profile and follow up of 26 children. Indian Pediatr 44: 333 338. [Crossref]

13. Yukset H, Yilmaz O, Saras R, Kirmaz C, Sogut A, et all (2007) Pulmonary hemosiderosis with normocomplentemic urticarial vasculitis in a child. Monaldi Arch Chest Dis 67: 63-67. [Crossref]

14. Hancock BJ, Dilorenzo M, Youssef S, Yazbeck S, Marcotte JE, et all (1993) Childhood primary pulmonary neoplasms. J Pediatric Surg 28: 1133-1136. [Crossref]

15. Wetmore RF, Handler SD, Patsic WP (1982) Pediatric tracheostomy: experience during the past decade. Ann Otol Rhinol Laryngol 91: 628-632. [Crossref]

16. Fabian MC, Smitheringale A (1996) Hemoptysis in children: the hospital for sick children experience. J Otolaryngol 25: 44-45. [Crossref]

17. Baktari JB, Tashkin DP, Small GW (1994) Factitious hemoptysis: adding to the differential diagnosis. Chest 105: 943-945.

18. Sood M, Clarke JR, Murphy MS (1999) Covert biting of buccal mucosa masquerading as haemetemesis or hemoptysis in children. Acta Paediatr 88: 1038-1040. [Crossref]

19. Godfrey S (2004) Pulmonary hemorrhage/ hemoptysis in children. Pediatric Pulmonol 37: 476-484. [Crossref]

20. Baby NPS, Gahunia HK, Massicotte P (2005) Pulmonary thromboembolism in children. Pediatric Radiol 35: 258-274

21. Bousseta K, Siala N, Brini I, Aloui N, Sammoud A, et al (2005) The hydatid of lung in children: 54 cases. Tunis Med 83: 24-27.

22. Menon P, Rao KL, Saxena AK (2004) Duplication cyst of the stomach presenting as hemoptysis. Eur J Pediatric Surg 14: 429-431. [Crossref]

23. Chan EY, Avcin T, Manson D, Cutz E, Scneider R, et al (2007) Massive hemoptysis in a 11-year-old girl with isolated pulmonary arteritis. Pediatr Pulmonol 42: 177-180. [Crossref]

24. Martire B, Loizzi M, Cimmino A, Perazzi S, De Mattin D, et al (2007). Catamenia hemoptysis from endobronchial endometriosis in a child with type I von Willebrand disease. Pediatr Pulmonol 42: 386-388. [Crossref]

25. Fernando HC, Stein M, Benfield JR, Link DP (1998) Role of bronchial artery embolization in the management of hemoptysis. Arch Surg. 133: 862-86. [Crossref]

26. Lee YJ, Lee SM, Park JS, Yim JJ, Yang SC,et al (2012) The clinical implications of bronchoscopy in hemoptysis patients with no explainable lesions in computed tomography. Respir Med 106: 413-9. [Crossref]

Copyright: (C2018 Rahman A. This is an open-access article distributed under the terms of the Creative Commons Attribution License, which permits unrestricted use, distribution, and reproduction in any medium, provided the original author and source are credited. 